\title{
Treatment of Severe Pseudomonas Infections of the Bronchi
}

\author{
A. PINES, ${ }^{*}$ M.D., F.R.C.P.ED.; H. RAAFAT, † D.M., M.R.C.P.GLAS.; G. M. SIDDIQUI, $\ddagger$ M.B., B.S. \\ J. S. B. GREENFIELD, $\$ M.B., B.S.
}

\begin{abstract}
Summary: Experience in treating 81 patients with severe bronchial infection with Pseudomonas aeruginosa is described. For those who were desperately ill high doses of intravenous carbenicillin $(18 \mathrm{~g}$. or more daily) were successful, even when initial carbenicillin resistance was present. For those who were less desperately ill lower doses of carbenicillin together with high doses of gentamicin (given both intramuscularly and by aerosol) comprised the treatment of choice. Gentamicin alone or colistin gave little or no benefit and cannot be recommended.
\end{abstract}

\section{Introduction}

Pseudomonas bronchial infections have become an increasing problem. Often they are superinfections in very advanced and debilitated patients, previously treated with many antibiotics; though in these cases the long-term prognosis is obviously poor, the distress caused by these infections is sufficient justification to seek alleviation.

Several antibiotics are claimed to be effective in pseudomonas infections; we therefore describe our experience with them in 81 cases treated during the past six years.

\section{Materials and Methods}

Our criteria for the inclusion of patients for treatment were strict. Heavy growth of Pseudomonas aeruginosa is often reported but frequently seems to be of no- significance. The criteria were: (1) chronic purulent bronchitis or bronchiectasis, the patients being severely ill with an infective exacerbation; (2) profuse growth of Ps. aeruginosa in at least three consecutive specimens of sputum before treatment; and (3) failure to respond to up to four courses of other antibiotics, such as tetracycline, penicillin with or without streptomycin, cephaloridine, ampicillin, and chloramphenicol, all in high doses.

Assessments.-These were all blind; the assessors were not connected with the daily treatment of these patients, and did not know whether the patients were having antibiotics. (1) A 24-hour specimen of sputum was measured daily for the presence or absence of pus and for quantity. (2) A clinical assessment of improvement or deterioration was done several times weekly. (3) White cell count, sedimentation rate, $\mathbf{P C O}_{2}$, and peak flow rate were measured before and after treatment. (4) Three specimens of sputum were cultured before and after treatment. (5) Each patient's opinion was sought during and after treatment.

The Study.-The antibiotics whose effects were investigated were colistin, gentamicin, carbenicillin, and gentamicin combined with carbenicillin. Changes in the investigations under

\footnotetext{
*Consultant Physician, Ware Park Hospital, Ware, and Herts and Essex Hospital, Bishop's Stortford, Herts. Clinical Assistant, Ware Park Hospital, Ware, Herts.

$¥$ Registrar, Ware Park Hospital, Ware, Herts.

SSenior Hospital Medical Officer, Ware Park Hospital, Ware, Herts.
}

heading 3 were often too small to help assessment and are not discussed further.

\section{Earlier Studies}

\section{Results}

The patients treated in these two studies were middle-aged or elderly males, severely ill with long-standing purulent bronchitis or bronchiectasis, and often in respiratory failure. More details concerning some of those treated with colistin or gentamicin have been given in an earlier study (Pines et al., 1967).

\section{Colistin}

The treatment given was 4-6 million units of colistin daily by the intramuscular route and 2-6 million units by inhalation in a Collison or Bird apparatus, both daily in three or four divided doses for 7 to 10 days. All the cultures were sensitive to discs containing $50 \mu \mathrm{g}$. of colistin. The treatment completely failed in all the 19 patients treated, the sputum, the clinical, and the patients' own assessments all agreeing. Five patients deteriorated seriously during the first days of treatment-three with peripheral circulatory collapse and fever. The inhalations were badly tolerated by three patients. No toxic effects were noted, nor were there abnormalities in routine blood transaminases, urea, or urine constituents.

\section{Gentamicin}

Twenty-eight patients were treated. Eight were given $120 \mathrm{mg}$. two or three times daily for seven days, followed by the same or slightly lower amounts for another seven days, by the intramuscular route. Eight were given an aerosol of $20-80 \mathrm{mg}$. in $5 \mathrm{ml}$. of normal saline four times daily, either with a Bird positive-pressure apparatus or a Collison nebulizer, for one to two months. Twelve patients were given gentamicin by both routes for two weeks in the above doses. Four pretreatment cultures were resistant to $10 \mu \mathrm{g}$., and the remainder sensitive (disc tests).

In five patients the sputum became mucoid after treatment, accompanied by clinical improvement, though in two the organisms could still be isolated in several specimens. In another three the organisms disappeared from the sputum after treatment, though it remained purulent. In 16 out of 22 instances of bacteriological failure resistance to a $10 \mu \mathrm{g}$. disc emerged. None of the 22 improved objectively or subjectively.

Mild dizziness occurred in three of these patients, all with a blood level of gentamicin of $10 \mu \mathrm{g}$. or more (Pines et al., 1967). When the dose was lowered or the treatment ended the dizziness disappeared. These results were not remarkable, though better than with colistin.

\section{Later Studies \\ Carbenicillin}

This antibiotic seemed more promising for our unfortunate patients (Knudsen et al., 1967). Further bacteriological work 
has suggested advantages of a combination with gentamicin (Brumfitt et al., 1967). We have treated 34 patients either with carbenicillin alone or combined with gentamicin. All were men - six aged 51 to 60,14 aged 61 to 70 , and 14 over 70 . The mean duration of their symptoms of bronchitis was $19 \cdot 1$ years. At the beginning of treatment their mean arterial carbon dioxide tension was $53.3 \mathrm{~mm}$. $\mathrm{Hg}$, and oxygen $51.1 \mathrm{~mm}$. $\mathrm{Hg}$. The mean peak flow rate was 119 litres/minute and the mean daily quantity of sputum $71.1 \mathrm{ml}$. These features were the same as in the patients in the earlier studies.

Carbenicillin Given Intramuscularly and by Aerosol.-The daily dose was $4-8 \mathrm{~g}$. by injection, $4 \mathrm{~g}$. in $20 \mathrm{ml}$. of saline by aerosol, and to enhance blood levels (Knudsen et al., 1967) $4 \mathrm{~g}$. of probenecid by mouth, all in four divided doses a day for 7 to 14 days. Larger amounts of carbenicillin intramuscularly are too painful. Fifteen patients were treated. In seven there was pronounced clinical improvement with clearing of the sputum to mucoid. In five the clinical improvement was slight and in three the treatment failed completely. In the 12 who improved pseudomonas organisms could not be cultured from the sputum after treatment. The patients were observed for up to two months in hospital afterwards. By the second week two had relapsed with pseudomonas infections, six relapsed by the fourth week, and four remained free from pseudomonas infection two months later. These results were certainly better than with gentamicin or colistin, but as there was little or no clinical improvement in more than half the patients we wished to improve the treatment.

Carbenicillin with Gentamicin.-The regimen consisted of carbenicillin in the above doses, together with gentamicin $100 \mathrm{mg}$. three times daily given intramuscularly and an aerosol of $40 \mathrm{mg}$. four times daily, together with probenecid as above. These were given for two weeks. Twelve patients were treated. In eight there was pronounced clinical and sputum improvement, in two there was slight improvement, and in two the treatment failed. In the 10 who improved pseudomonas organisms could not be cultured from the sputum afterwards. By two weeks later two patients had relapsed with pseudomonas infections, two relapsed during the second month, and six still had no evidence of pseudomonas infection up to four months later. All patients tolerated the treatment well; very ill patients, however, may not co-operate with intensive aerosol treatment. There were no side-effects, including dizziness; but blood levels of gentamicin were not determined. The numbers are small and the differences not significant statistically, but there was much more clinical improvement, with fewer relapses, and we were satisfied that this combined treatment was better than that with carbenicillin alone.

Carbenicillin Intravenousiy.-This was given in a dose of $18 \mathrm{~g}$. daily by slow intravenous drip over 24 hours of 1.5 to 2 litres of $5 \%$ glucose saline, for up to seven days, followed by intramuscular carbenicillin as before for another seven days. Seven patients were treated. Six had had previous courses of carbenicillin, in our or other hospitals, and the cultures were repeatedly resistant to carbenicillin discs of $25 \mu \mathrm{g}$. strength. They were all desperately ill and we wished to see if very high doses of carbenicillin could overcome this apparent resistance. Four of these patients showed great improvement, two improved slightly, and in one there was failure. In six out of seven there was complete clearance of pseudomonas organisms from the sputum and in five the sputum was still clear two months later; thus, despite the presence of apparent resistance, the treatment was usually successful.

\section{Bacteriology}

Routine disc tests were done for sensitivity, the strength for gentamicin being $10 \mu \mathrm{g}$. per disc and for carbenicillin $25 \mu \mathrm{g}$. In three of the 15 patients treated with carbenicillin alone the treatment failed to eradicate pseudomonas organisms, and in two of them cultures resistant to discs of $25 \mu \mathrm{g}$ of carbenicillin appeared, as in six of the patients who relapsed after treatment. With combined carbenicillin and gentamicin, carbenicillin resistance appeared in one of the patients where the treatment failed and in two who relapsed later, but in only one was there resistance to the $10-\mu \mathrm{g}$. disc of gentamicin.

\section{Deaths}

All six patients whose clinical state did not improve with treatment died. Among 13 patients in whom pseudomonas infection reappeared, 10 died.

\section{Discussion}

Genuine pseudomonas infections are of very serious import. That this organism was pathogenic in our patients is strongly suggested by profuse and repeated growth on culture and persistence despite many courses of chemotherapy, which might have cleared more commonly occurring infections such as those of Haemophilus influenzae and Streptococcus pneumoniae.

Many of the patients probably had bronchiectasis, in which precipitin tests for pseudomonas antibodies are commonest (Burns and May, 1968). Most of the patients treated earlier with colistin or with gentamicin alone died, as did those who did not respond or who relapsed with our more recent treatments; profuse growths of pseudomonas were cultured from their sputum repeatedly before death and the organism must have been pathogenic.

Colistin in our patients was useless and in some even deleterious, despite very high combined intramuscular and aerosol dosages. We cannot confirm others' success in apparently similar cases (Halliday, 1967). Gentamicin alone, given intramuscularly or with a combined intramuscular and aerosol technique, was a little better, but the results were far inferior to those sometimes claimed (Mariani and Velluti, 1969). Carbenicillin, given in a dose of up to $8 \mathrm{~g}$. intramuscularly together with $4 \mathrm{~g}$. by inhalation daily and with blood levels enhanced by probenecid, was much more successful in clearing pseudomonas organisms from the sputum, but had less pronounced effect on the patient's clinical state or on the purulence of the sputum. Comparable results have been described by others (Brumfitt et al., 1967; Stratford, 1968). When this regimen of carbenicillin was combined with a high dose of gentamicin intramuscularly and by aerosol, results seemed much better (Cooper et al., 1969).

In our patients carbenicillin protected against the emergence of gentamicin resistance, which occurred so frequently in our earlier cases treated with gentamicin alone. Gentamicin protected against carbenicillin resistance, but to a less extent. Synergy has been claimed to occur sometimes between these two antibiotics (Brumfitt et al., 1967), but we have not been able to distinguish between this and an additive clinical effect in our patients. We hope to pursue this question in later researches.

Finally, when carbenicillin resistance appears the intravenous technique using $18 \mathrm{~g}$. or more of carbenicillin seems to overcome this (Stratford, 1968), though it is too tedious to employ routinely. Unfortunately our laboratory information was not sufficient to determine the exact levels of resistance which can be overcome by this means. Judging by our results, degrees of resistance which preclude response to even the largest doses of carbenicillin may be rare.

After intramuscular injection sputum concentrations of gentamicin may approach those in blood (Pines et al., 1967), though the concentrations may be further enhanced by aerosol treatment. Larger intramuscular doses, which might be more successful, cannot be given for fear of vestibular or renal toxicity. Carbenicillin can safely be given in very high doses, 
though pain limits the amount which can be given intramuscularly. Sputum levels are much lower than those in blood (J. R. May, personal communication, 1969). The drug must therefore also be given by aerosol in order to attain sufficient intrabronchial concentration.

In patients with renal failure (all our patients had blood ureas below $60 \mathrm{mg} . / 100 \mathrm{ml}$.) carbenicillin alone might be the safest treatment available (Eastwood and Curtis, 1968).

We thank the nursing and secretarial staff of Ware Park and the Herts and Essex Hospitals; Dr. W. D. Linsell and Dr. W. Mavor and staff, Pathology Laboratory, Hertford County and Herts and Essex Hospitals; Dr. E. T. Knudsen, Beecham Research Laboratories, for supplies of carbenicillin; Professor J. W. Crofton, Uni- versity of Edinburgh, for criticism; and the physicians who sent us their patients.

REFERENCES

Brumfitt, W., Percival, A., and Leigh, D. A. (1967). Lancet, 1, 1289.

Burns, M. W., and May, J. R. (1968). Lancet, 1, 270.

Cooper, R. G., Rice, J. C., and Penfold, J. L. (1969). Medical fournal of Australia, 1, 517

Eastwood, J. B., and Curtis, J. R. (1968). British Medical fournal, 1, 486.

Halliday, N. P. (1967). Clinical Trials fournal, 4, 771.

Knudsen, E. T., Rolinson, G. N., and Sutherland, R. (1967). British Medical fournal, 3, 75 .

Mariani, G., and Velluti, G. (1969). Paper read at the 6th International Conference of Chemotherapy, Tokyo.

Pines, A., Raafat, H., and Plucinski, K. (1967). British Medical fournal, 2, 543.

Stratford, B. C. (1968). Medical fournal of Australia, 2, 890.

\title{
Increased Sebum Excretion in Patients with Breast Cancer
}

\author{
J. L. BURTON,* M.B., B.SC., M.R.C.P. ; W. J. CUNLIFFE, † M.B., B.SC., M.R.C.P. ; SAM SHUSTER, † PH.D., M.B., F.R.C.P.
}

British Medical fournal, 1970, 1, 665-666

Summary: The rate of sebum excretion from the fore$N$ head skin of patients with early breast cancer was found to be just significantly higher than in age-matched control women. This may indicate that some breast cancer patients have an increase in circulating or tissue-bound sebotrophic hormones, or a decrease in their inhibitors.

\section{Introduction}

A variety of exogenous steroid hormones and ablative endocrine procedures are known to affect the course of advanced breast cancer, but the response in an individual case is relatively unpredictable (Stoll, 1969). In view of the present uncertainty regarding the hormonal status of patients with breast cancer it is relevant to study the activity of other organs known to be under hormonal control. Krant et al. (1968) found a seborrhoea in patients with advanced breast cancer, and we have compared the sebum excretion rates in patients with early breast cancer and a matched group of control subjects.

\section{Method and Subjects}

The sebum excretion rate was measured by the method of Strauss and Pochi as modified by Cunliffe and Shuster (1969a).

In all subjects three-hour sebum collections were done at the same time in the afternoon, from two equal areas of skin at opposite sides of the forehead. Sebum collections were made preoperatively on patients after their admission to hospital for biopsy of a lump in the breast which was clinically suspected to be early carcinoma. Twenty patients (aged 42 to 75 years) were found at operation to have breast cancer. None of them had evidence of metastasis, and none had received hormonal therapy. As control subjects we used age-matched women from the medical wards who were convalescing from benign diseases such as acute bronchitis, peptic ulcer, acute pyelonephritis, cerebral thrombosis, etc. None of these patients was pyrexial and none was known to have any endocrine dysfunction. Because of our recent finding (Cunliffe and Shuster, $1969 \mathrm{~b}$ ) of the importance of a previous history of adolescent acne in the interpretation of sebum excretion rates in subsequent years all patients were asked about previous acne and

* Senior Registrar, Royal Victoria Infirmary, Newcastle upon Tyne. † Consultant Dermatologist, Leeds General Infirmary.

F Professor of Dermatology, Royal Victoria Infirmary, Newcastle upon Tyne NE1 4LP. were examined for acne scarring. We made no attempt to match patients with regard to acne as this could have masked a difference in hormonal status in the two groups. Six of the cancer patients and five of the controls were premenopausal.

\section{Results}

The results are given in the Table. The mean sebum excretion rate was $0.61 \mu \mathrm{g} / \mathrm{sq} . \mathrm{cm} . / \mathrm{min}$. \pm 0.07 in the cancer patients and $0.42 \mu \mathrm{g} . / \mathrm{sq} . \mathrm{cm} . / \mathrm{min} . \pm 0.08$ in the control group. The mean difference between cancer patients and their paired controls was $+0 \cdot 19$, and this difference was just significant $(\mathrm{p}<0.05, t$ value with 19 D.F. $=2.15$ ).

Sebum Excretion Rates. Each Rate is the Mean of Two Observations, One From Each Side of the Forehead

\begin{tabular}{|c|c|c|c|c|c|}
\hline \multirow{2}{*}{$\begin{array}{l}\text { Age of } \\
\text { Patient }\end{array}$} & \multicolumn{2}{|c|}{$\begin{array}{l}\text { Sebum Excretion Rates } \\
(\mu \mathrm{g} . / \mathrm{sq} . \mathrm{cm} . / \mathrm{min} .)\end{array}$} & \multirow{2}{*}{$\begin{array}{l}\text { Age of } \\
\text { Patient }\end{array}$} & \multicolumn{2}{|c|}{$\begin{array}{l}\text { Sebum Excretion Rates } \\
(\mu \mathrm{g} . / \mathrm{sq} . \mathrm{cm} \cdot / \mathrm{min} .)\end{array}$} \\
\hline & Cancer & Control & & Cancer & Control \\
\hline $\begin{array}{l}42 \\
45 \\
47 \\
50 \\
50 \\
50 \\
52 \\
52 \\
55 \\
57\end{array}$ & $\begin{array}{r}0.97 \\
0.69 \\
+1.11 \\
0.71 \\
0.39 \\
0.33 \\
01.03 \\
0.60 \\
0.90 \\
0.66\end{array}$ & $\begin{array}{l}0.22 \\
0.36 \\
0.33 \\
0.41 \\
0.56 \\
0.19 \\
1.06 \\
0.43 \\
\begin{array}{l}1.33 \\
1.01\end{array}\end{array}$ & $\begin{array}{l}58 \\
58 \\
59 \\
64 \\
64 \\
64 \\
65 \\
67 \\
70 \\
75\end{array}$ & $\begin{array}{l}0.67 \\
0.09 \\
0.35 \\
0.75 \\
0.32 \\
0.37 \\
0.56 \\
1.16 \\
0.29 \\
0.32\end{array}$ & $\begin{array}{l}0.60 \\
0.40 \\
0.34 \\
0.03 \\
0.13 \\
0.09 \\
0.33 \\
0.10 \\
0.18 \\
0.37\end{array}$ \\
\hline
\end{tabular}

*Previous acne

\section{Discussion}

Our finding of an increased rate of sebum excretion in patients with breast cancer is in agreement with the finding of Krant et al. (1968). We would emphasize, however, that the significance of the difference between our patients with breast cancer and the paired controls is not great.

The difficulty of obtaining suitable controls for breast cancer patients has been discussed by Bulbrook and Hayward (1969). Little is known of the effect of factors such as apprehension and prolonged illness on sebaceous activity. The ideal subjects for our control series would have been women admitted for biopsy of benign breast disease, but as it was not possible to obtain age-matched subjects relatively "fit" medical patients were used. It is apparent that our results will need further confirmation in a larger series of cases, preferably with several control series from different sources. 